\title{
The effects of surgically treated pulmonary stenosis on lung growth and cardiopulmonary function in children during rest and exercise
}

\author{
M. Rosenthal, A. Bush
}

\begin{abstract}
The effects of surgically treated pulmonary stenosis on lung growth and cardiopulmonary function in children during rest and exercise. M. Rosenthal, A. Bush. (C)ERS Journals Ltd 1999.

ABSTRACT: The effects of high pulmonary blood flow and pressure on pulmonary development are well understood, but the effect of low pulmonary flow/pressure is not. Pulmonary stenosis (PS) was therefore used as a model to determine its effect on lung development, which was assessed noninvasively by carbon monoxide transfer at rest and during exercise.

One hundred and six control children (55 males, 8-16 yrs) and 11 children with isolated valvar or subvalvar PS surgically corrected $\geq 10$ yrs prior to the study without residual stenosis/regurgitation were evaluated. Measurements of effective pulmonary blood flow, stroke volume, arteriovenous oxygen difference (AVO), transfer factor and transfer constant, alveolar ventilation and anaerobic threshold were performed using a mass spectrometer. Data from the normal children allowed calculation of z-scores for the study group matched for age, sex, pubertal stage and surface area.

PS children at rest had a significantly lower forced expired volume in one second, cardiac frequency and transfer constant with a raised oxygen consumption and AVO which persisted on exercise. During exercise, the cardiac frequency was 12 beats $\cdot \mathrm{min}^{-1}$ slower and AVO $0.017 \mathrm{~L}$ greater than controls $(\mathrm{p}<0.05)$. A persistently mildly raised effective functional residual capacity $\left(0.2 \mathrm{~L} \cdot \mathrm{m}^{-2}\right)$ during exercise led to a reduced transfer constant $\left(0.35 \mathrm{mmol} \cdot \mathrm{min}^{-1} \cdot \mathrm{kPa}^{-1} \cdot \mathrm{L}^{-1}\right)$, although the percentage rise $(28 \%)$ from rest to peak exercise was normal. The percentage fall in stroke volume from the penultimate exercise stage to peak exercise stage was greater in PS children (24\%, 95\% confidence interval 11-37) than control children $(2.4,-2-10, p<0.005)$.

In conclusion, although the effects are small, pulmonary stenosis does affect cardiopulmonary function after surgery. This needs to be considered when contemplating the timing of treatment.

Eur Respir J 1999; 13: 590-596.
\end{abstract}

Dept of Paediatric Respiratory Medicine, The Royal Brompton Hospital, London, UK.

Correspondence: M. Rosenthal

Dept of Paediatric Respiratory Medicine

The Royal Brompton Hospital

London SW3 6NP

UK

Fax: 441713518763

Keywords: Children

exercise

haemodynamics

lung growth

pulmonary stenosis

surgery

Received: June 41998

Accepted after revision October 111998

Funded by Innovision PLC, Denmark.
The effects of a high pulmonary blood flow and pressure on the lung and its vasculature are well known [1-4] and are characterized by: initially, an abnormal extension of vascular smooth muscle into the peripheral pulmonary arteries (Rabinovitch grade A), progressing to an increase in percentage arterial wall thickness (grade B), and finally leading to a reduction in the total number of small pulmonary arteries (grade $\mathrm{C}$ ). These grades bear a strong correlation to the pulmonary artery pressure and vascular resistance. In contrast, conditions leading to a low postnatal pulmonary artery flow/pressure have been less extensively researched. Neonates with pulmonary atresia histologically possess fewer, smaller and thinner pulmonary arteries, although the longitudinal distribution of their muscularization is normal [5]. They thus have a raised alveolar/arterial ratio. Their bronchial arterial supply, however, was normal. In contrast, older children with a tetralogy of Fallot have an increased intra-acinar arterial and venous vessels [6] with a normal branching pattern. The larger arteries were of reduced calibre with a thicker muscular coat, and there was also a reduced alveolar number and total lung volume. Whether these effects are different to those in pulmonary atresia because of the older age group or palliative surgery in some is uncertain. In a situation where inadvertent surgical ligation of the pulmonary artery occurred in infancy, at death 3 yrs later, histology showed small alveoli with thickened walls [7].

In any event, pathologists in this field [8] admit that "There is little more to be gained in correlating structure and function in the traditional manner. The emphasis is shifting to in vivo assessment..."

Carbon monoxide transfer can be used as an indirect measure of the size of the alveolar capillary unit [9-14]. The value is approximately proportional to the pulmonary capillary volume and can be expressed either as whole lung carbon monoxide transfer $(T \mathrm{~L}, \mathrm{CO})$ or as the value per litre of accessible lung volume, the transfer constant (KCO). On exercise, alveolar capillary units are recruited, and there is 
some distension of the pulmonary capillary bed. One may hypothesize that $T \mathrm{~L}, \mathrm{CO}$ and $K \mathrm{CO}$ could be normal at rest, but fail to rise appropriately on exercise. Thus, a full description of the functional state requires information concerning gas transfer not only at rest but also during exercise. It was hypothesized that these functional measurements will allow noninvasive assessment of structure and in particular growth of the alveolar capillary unit.

In humans, alveoli with their accompanying capillary network develop from about 26 weeks' gestation and are complete in number after about 2 yrs post-delivery $[15$, 16]. Damage to this process continuing after the second birthday cannot be compensated for by future "catch-up" growth.

This study, therefore, applies these techniques to a group of children treated surgically for isolated pulmonary stenosis (PS), a low pulmonary pressure/flow condition.

\section{Methods}

The study received local ethical committee approval, and written informed consent was obtained from all the children's parents.

\section{The control group}

The control group has been fully described elsewhere [17-19] and consists of 106 (55 males) healthy children aged $>7.5 \mathrm{yrs}$ and $125 \mathrm{~cm}$ tall (the minimum age and size which ensured cooperation with the exercise protocol), with no history of recent acute or significant, chronic respiratory illness and receiving no medications. To ensure that the control group was not biased towards more physically active children, volunteers were targeted "to undertake studies on how the heart and lungs worked together" rather than on the basis of testing their fitness; members of school athletic clubs were excluded [17].

\section{The study group}

The entry criteria were those for control children plus isolated valvar or subvalvar PS repaired at surgery by a single surgeon at least $\geq 10$ yrs prior to study and with no postoperative complaints. In particular, a patent arterial duct was an exclusion criterion. Seventeen children conformed to these criteria over a 9-yr period. Six out of 17 lived abroad; the remaining 11 were traced and all participated (table 1).

All children had their height, weight, two-site skinfold thickness and pubertal stage assessed. Resting lung function using a "Compact" spirometer (Vitalograph, Lenexa, KS, USA) was also measured according to American Thoracic Society standards [20] and compared with UK normal ranges [21]. The study children also received a two-dimensional and M-mode echocardiography to check the right ventricular performance and any residual stenosis/ regurgitation.

\section{Protocol}

This has been fully described previously [17-19]. Briefly, following a 1-h fast, anthropometric and spirometric measurements were obtained. The subjects then practised with the mass spectrometry equipment, rested for
$10 \mathrm{~min}$ and then performed, seated, five 20-s rebreathing manoeuvres (bag volume: $40 \%$ of predicted vital capacity) from functional residual capacity (FRC), every 3 min for $15 \mathrm{~min}$.

After the resting measurements, the subject exercised using an electromagnetic bicycle (Seca 100; Birmingham, UK). After a 3-min rest, the subject performed a 12-s rebreathing manoeuvre, and then began cycling, initially backwards at zero load to loosen up and then forwards, at $25 \mathrm{~W} \cdot \mathrm{m}^{-2}$, increasing in $15 \mathrm{~W} \cdot \mathrm{m}^{-2}$, increments every $3 \mathrm{~min}$ until exhaustion. During the last $20 \mathrm{~s}$ of each 3-min stage, children performed a 12 -s rebreathing manoeuvre whilst continuing to pedal. At exhaustion, children stopped pedalling but remained on the bicycle for a further $9 \mathrm{~min}$, performing three further 12-s rebreathing manoeuvres. In addition, between rebreathing manoeuvres, the subject's expired gas was continuously analysed. During the study, the pulse rate and arterial saturation of the subject was monitored continuously using a surface oximeter (Nellcor, Hayward, CA, USA) placed over the right supraorbital artery. A typical study lasted 75 min during which the child performed 12-16 rebreathing manoeuvres.

\section{Measurements}

The methods for obtaining the physiological measurements used inert gas rebreathing and helium dilution mixed expired gas analysis. Briefly, rebreathing from a bag containing non-native gases allows equilibrium with the gases in the respiratory system. From this closed system, the rate of uptake of a soluble gas into the pulmonary blood stream is used to calculate the "effective" pulmonary blood flow, namely that part which is in contact with ventilated alveoli [22-26]; and with knowledge of the cardiac frequency, the effective stroke volume was found. The uptake of oxygen from the same closed system allows measurement of oxygen consumption. Use of the Fick equation allows the arteriovenous oxygen content difference (AVO) to be calculated from the ratio of oxygen consumption to pulmonary blood flow. The mixing and dilution of a test insoluble gas with the native lung gas during rebreathing allowed calculation of "effective" FRC [24] and will be different from the true FRC as it is only that portion of respiratory gas that may mix.

Table 1. - Characteristics of study group

\begin{tabular}{rccccc}
\hline Subject & Sex & $\begin{array}{c}\text { Age at } \\
\text { surgery } \\
\text { yrs }\end{array}$ & $\begin{array}{c}\text { Age at } \\
\text { study } \\
\text { yrs }\end{array}$ & $\begin{array}{c}\text { Pubertal } \\
\text { stage } \\
\text { Tanner }\end{array}$ & $\begin{array}{c}\text { Surface } \\
\text { area } \\
\mathrm{m}^{2}\end{array}$ \\
\hline 1 & $\mathrm{M}$ & 0.14 & 10.8 & 1 & 1.1 \\
2 & $\mathrm{M}$ & 0.98 & 11.5 & 1 & 1.1 \\
3 & $\mathrm{M}$ & 0.98 & 12.1 & 1 & 1.1 \\
4 & $\mathrm{M}$ & 2.35 & 12.3 & 3 & 1.4 \\
5 & $\mathrm{M}$ & 1.39 & 13.6 & 4 & 1.6 \\
6 & $\mathrm{M}$ & 3.12 & 13.6 & 3 & 1.3 \\
7 & $\mathrm{M}$ & 3.52 & 14.2 & 3 & 1.4 \\
8 & $\mathrm{M}$ & 4.54 & 15.9 & 3 & 1.5 \\
9 & $\mathrm{~F}$ & 1.76 & 12.3 & 3 & 1.5 \\
10 & $\mathrm{~F}$ & 1.10 & 12.7 & 4 & 1.6 \\
11 & $\mathrm{~F}$ & 2.31 & 14.9 & 3 & 1.5 \\
\hline
\end{tabular}

M: male; F: female. 
Helium dilution mixed expired gas analysis [27] adds a marker gas (helium) at a known calibrated rate to the subjects expired ventilation in a mixing box. The extent of its dilution essentially measures minute ventilation, and from the concentration of the components of inspired air, oxygen consumption, carbon dioxide production and therefore the anaerobic threshold [28] and respiratory quotient can be derived. By placing a second sampling probe at the mouth, end-expired (alveolar) carbon dioxide can be measured, and its ratio to the mean concentration in the mixing box is used to calculate the physiological fractional dead space and alveolar ventilation.

\section{The mass spectrometer and gas mixtures}

The study used an Innovision 2000 mass spectrometer (Innovision, Odense, Denmark). It separates gases by their mass:charge ratio, and their concentration is proportional to their amplified electrical signal. By comparing the signal with a calibration gas, concentrations can be calculated. Errors owing to changes in gas viscosity, the addition of exhaled water vapour or electrical drift were avoided by ensuring that the total electrical signal represented $100 \%$ of the gas with the known components correctly apportioned (automatic total pressure correction).

The calibration gases (tolerance $\pm 2 \%, \mathrm{BOC}$, London, UK) had a typical make-up of $0.3 \%$ acetylene, $1 \%$ argon, $1 \%$ helium, $3 \%$ sulphur hexafluoride, $5 \%$ carbon dioxide, $25 \%$ oxygen and balance nitrogen. This tolerance for highconcentration gases was further refined by the spectrometer using a known concentration of oxygen in room air, $20.93 \%$.

The rebreathing test gas had typical contents of $0.3 \%$ carbon monoxide (of stable isotope ${ }^{180}$ ), $0.3 \%$ acetylene (the soluble gas), 35\% oxygen, 5\% sulphur hexafluoride (the insoluble, inert gas), 35\% oxygen and balance nitrogen. These cylinders were of absolute grade (zero error, BOC) and all gases were certified of medicinal quality. The ideal rebreathing bag gas volume was found from a pilot study to be $40 \%$ of the subject's predicted forced vital capacity. This allowed complete emptying with minimal effort at rest but was sufficiently large for all stages of exercise.

\section{Analysis}

All traces were visually checked to ensure the correct point of complete mixing of the rebreathing bag and lung gases, and to exclude pulmonary recirculation of the rebreathing gases which distorts the measurements. Only the middle $40 \%$ of the exhaled breath was analysed as this best represents alveolar gas concentration [20].

The healthy controls were used to derive age, surface area and sex determined mean results for all the parameters at rest and during each exercise stage [17]. Resting values were the average of the last three rebreathing measurements [23]. Control children were divided into four age groups $(8-10.5$ yrs, $n=23$; 10.6-12.5 yrs, $n=24 ; 12.6-14.5$ yrs, $n=37$; and $>14.5$ yrs, $n=22$ ) and three pubertal groups: pre $(n=30)$, early $(n=36)$ and late $(n=40)$ puberty based on Tanner stages 1, 2-3 and 4-5, respectively. From these normal results, z-scores were calculated such that for all control children taken together, their mean z-score for any parameter during rest or any stage of exercise was 0 with a standard deviation of 1 . Thus, during exercise, even though all raw values will change in the control group, their mean z-score remains zero. A deviation from mean zero in the study group during exercise is interpreted as the patient group not matching the changes expected rather than an absolute rise or fall in that parameter. This methodology allows comparison of the study group corrected for sex, age, surface area and pubertal stage.

In addition to the above and to avoid spurious comparisons between age groups and sexes, each subject's result (control and study) at the end of exercise and after 9 min recovery was expressed as a percentage change from their own original resting value, i.e. 100 (new value-resting value)/resting value. All children can now be compared at different peak workloads to determine their relative capabilities.

The maximum work performed by the patients was also expressed as a percentage of the median maximum work performed by each control sex and age group.

z-Score differences within each patient group were analysed using a two-way analysis of variance (ANOVA) with the subject as a blocking variable and Bonferroni's correction for multiple contrasts and $\mathrm{p}<0.05$ rejected the null hypothesis. z-Score differences between patient groups at each rest and exercise stage were analysed using the unpaired Student's t-test, and $\mathrm{p}<0.05$ rejected the null hypothesis. This methodology was used to strike a balance between the effects of multiple contrasts and the maximum reduction in the residual variance. Percentage differences were examined using the Mann-Whitney test.

\section{Results}

\section{Season}

Lung function z-scores demonstrated a lower forced expiratory volume in one second (FEV1) in subjects compared to controls (control mean z-score: $-0.04,95 \%$ confidence intervals (CI) $-0.32-0.25$; PS mean: $-1.14,-0.32--1.84$, $\mathrm{p}<0.001$ ), but there was a similar forced vital capacity and maximum expiratory flow at $50 \%$ of forced vital capacity. Echocardiography in the subject group showed a zero or

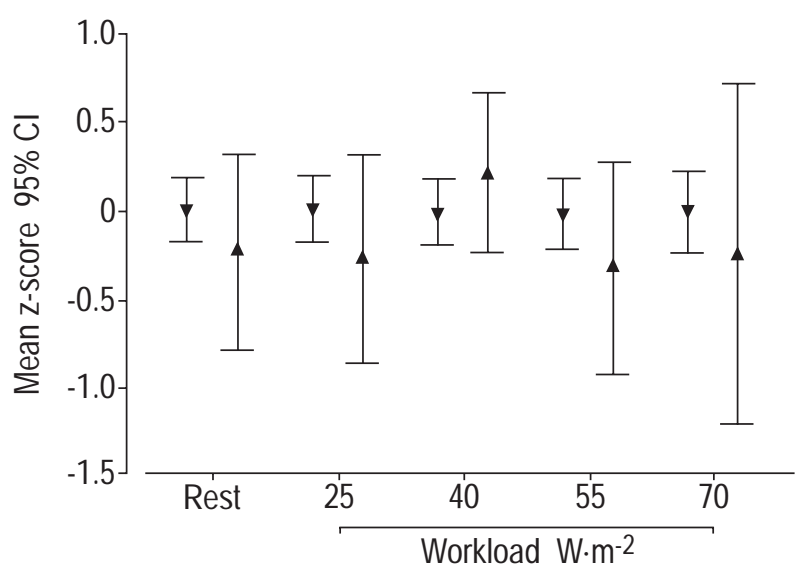

Fig. 1. - Mean (95\% confidence interval (CI)) z-scores for effective pulmonary blood flow in control children $\left(\mathbf{\nabla} ; \mathrm{n}=106\right.$, except at $55 \mathrm{~W} \cdot \mathrm{m}^{-2}$ $(\mathrm{n}=99)$ and $70 \mathrm{~W} \cdot \mathrm{m}^{-2}(\mathrm{n}=71)$ workloads $)$ and those after surgery for pulmonary stenosis $\left(\boldsymbol{\Delta} ; \mathrm{n}=11\right.$, except at $25 \mathrm{~W} \cdot \mathrm{m}^{-2}(\mathrm{n}=10)$ and $70 \mathrm{~W} \cdot \mathrm{m}^{-2}$ $(n=9)$ workloads) at rest and for each workload. 


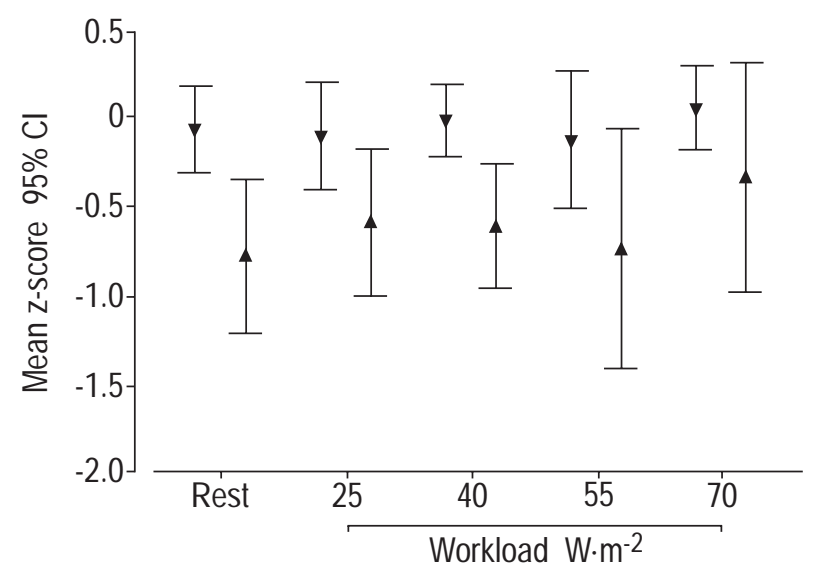

Fig. 2. - Mean (95\% confidence interval (CI) $\mathrm{z}$-scores for cardiac frequency in control children $\left(\mathbf{\nabla} ; \mathrm{n}=104\right.$, except at rest $(\mathrm{n}=103), 55 \mathrm{~W} \cdot \mathrm{m}^{-2}$ $(\mathrm{n}=97)$ and $70 \mathrm{~W} \cdot \mathrm{m}^{-2}(\mathrm{n}=70)$ workloads $)$ and those after surgery for pulmonary stenosis $\left(\boldsymbol{\Delta} ; \mathrm{n}=11\right.$, except at $70 \mathrm{~W} \cdot \mathrm{m}^{-2}(\mathrm{n}=9)$ workload $)$ at rest and for each workload.

negligible gradient in 10 of 11 children across the right ventricular outflow tract and one with a gradient of 5 $\mathrm{mmHg}$. Pulmonary regurgitation, if present, was trivial in all. The free wall of the right ventricle was of normal thickness and normal motion in all 11 subjects. There were no differences in height z-score (control (mean, 95\% CI): $0.43,0.24-0.63$; PS: $0.05,-0.61-0.69)$ or mean skinfold thickness z-score (control (mean, 95\% CI): 0.73, 0.580.89 ; PS: $0.50,0-1.01)$ between control and subject groups.

Effective pulmonary blood flow in PS children was no different to controls (fig. 1). The cardiac frequency (fig. 2) tended to be slower during exercise than controls to the extent of some 12 beats. $\mathrm{min}^{-1}$ at $55 \mathrm{~W} \cdot \mathrm{m}^{-2}(\mathrm{p}<0.05)$. There was no relationship between this effect and age at surgery. Stroke volume showed no consistent differences from controls (fig. 3). There was an increased oxygen requirement of the PS group from rest to $55 \mathrm{~W} \cdot \mathrm{m}^{-2}$ (fig. 4) amounting to a difference of $8 \mathrm{~mL} \cdot \mathrm{min}^{-1} \cdot \mathrm{m}^{-2}$ at rest and $30 \mathrm{~mL} \cdot \mathrm{min}^{-1} \cdot \mathrm{m}^{-2}$ at $55 \mathrm{~W} \cdot \mathrm{m}^{-2}$. From the Fick equation, this also led to a raised AVO (fig. 5). There was a trend for

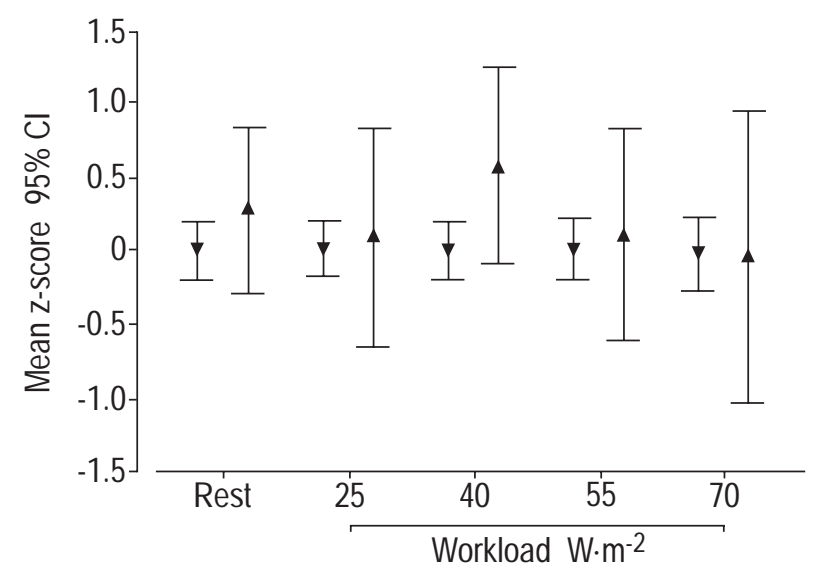

Fig. 3. - Mean (95\% confidence interval (CI)) z-scores for effective stroke volume in control children $\left(\boldsymbol{\nabla} ; \mathrm{n}=103\right.$, except at $55 \mathrm{~W} \cdot \mathrm{m}^{-2}(\mathrm{n}=96)$ and $70 \mathrm{~W} \cdot \mathrm{m}^{-2}(\mathrm{n}=70)$ workloads $)$ and those after surgery for pulmonary stenosis $\left(\boldsymbol{\Delta} ; \mathrm{n}=11\right.$, except at $25 \mathrm{~W} \cdot \mathrm{m}^{-2}(\mathrm{n}=10)$ and $70 \mathrm{~W} \cdot \mathrm{m}^{-2}(\mathrm{n}=9)$ workloads) at rest and for each workload.

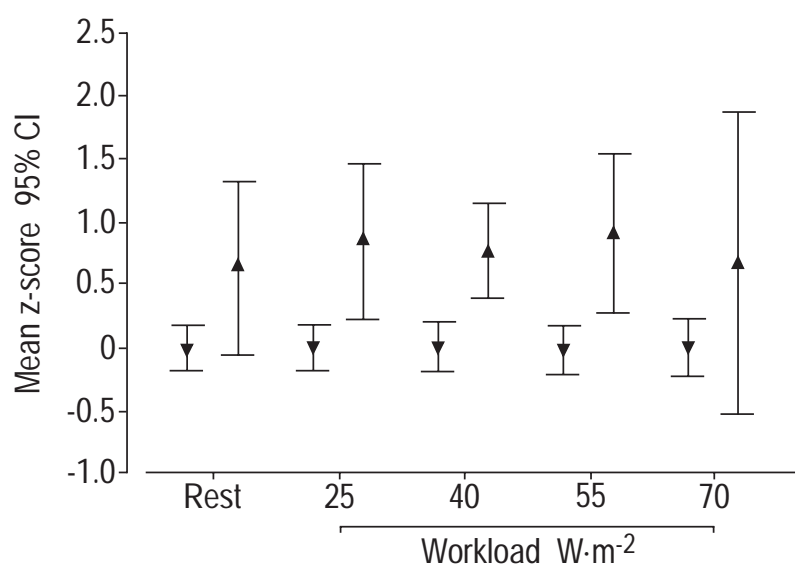

Fig. 4. - Mean (95\% confidence interval (CI)) z-scores for oxygen consumption in control children $\left(\mathbf{\nabla} ; \mathrm{n}=103\right.$, except at $55 \mathrm{~W} \cdot \mathrm{m}^{-2}(\mathrm{n}=96)$ and $70 \mathrm{~W} \cdot \mathrm{m}^{-2}(\mathrm{n}=70)$ workloads $)$ and those after surgery for pulmonary stenosis $\left(\Delta ; n=11\right.$, except at $25 \mathrm{~W} \cdot \mathrm{m}^{-2}(\mathrm{n}=10)$ and $70 \mathrm{~W} \cdot \mathrm{m}^{-2}(\mathrm{n}=9)$ workloads) at rest and for each workload.

this raised AVO to be related to time from surgery $(\mathrm{p}=$ $\left.0.08, r^{2}=0.26\right)$. The transfer factor was similar between control and study groups, but the study group had a raised FRC compared to the control (fig. 6), and thus the transfer constant was less than normal, particularly at rest (fig. 7).

The minute and alveolar ventilation at rest were significantly lower than controls, but were very similar during exercise. The physiological dead space was similar between groups at all stages (data not shown).

The percentage change from each child's own initial resting value at maximum exercise and after 9 min rest after exercise is shown in table 2 . The only significant differences are that at maximum exercise the treated PS group had a slightly faster cardiac frequency and a smaller stroke volume than controls. More importantly, a comparison of each child's stroke volume at their peak exercise stage to their stroke volume at their penultimate exercise stage demonstrated that in control children, the stroke volume fell by a mean of $2.4 \%$ (95\% CI $-2-10)$ compared to $24 \%(11-37)$ in the PS group $(\mathrm{p}<0.005$, Mann-Whitney). This fall in stroke volume was not

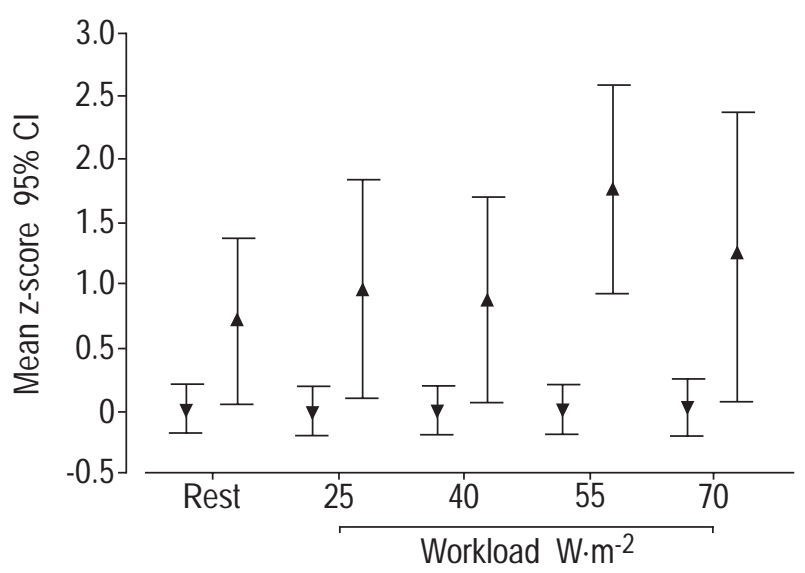

Fig. 5. - Mean (95\% confidence interval (CI)) z-scores for arteriovenous oxygen difference in control children $(\mathbf{\nabla} ; n=103$, except at 55 $\mathrm{W} \cdot \mathrm{m}^{-2}(\mathrm{n}=96)$ and $70 \mathrm{~W} \cdot \mathrm{m}^{-2}(\mathrm{n}=70)$ workloads $)$ and those after surgery for pulmonary stenosis $\left(\Delta ; n=11\right.$, except at $25 \mathrm{~W} \cdot \mathrm{m}^{-2}(\mathrm{n}=10)$ and 70 $\mathrm{W} \cdot \mathrm{m}^{-2}(\mathrm{n}=9)$ workloads) at rest and for each workload. 


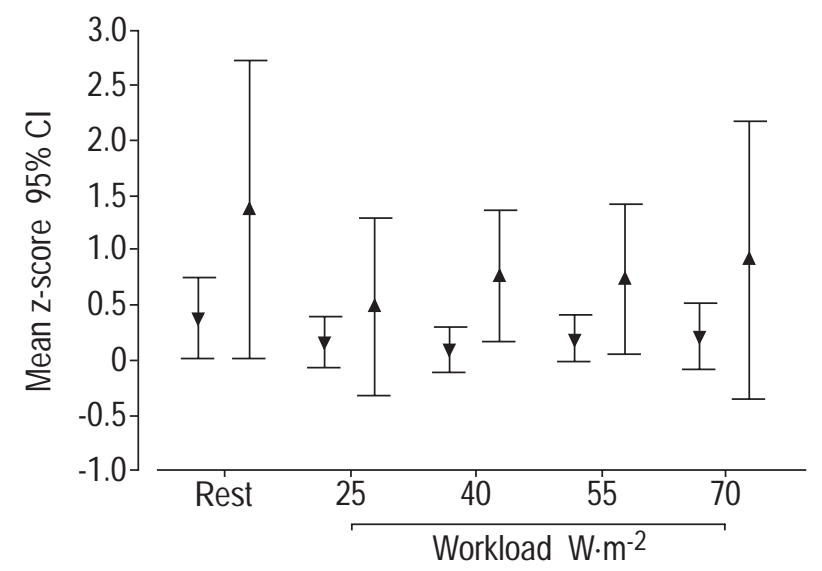

Fig. 6. - Mean (95\% confidence interval (CI)) z-scores for functional residual capacity in control children $\left(\mathbf{\nabla} ; \mathrm{n}=106\right.$, except at $55 \mathrm{~W} \cdot \mathrm{m}^{-2}$ $(\mathrm{n}=99)$ and $70 \mathrm{~W} \cdot \mathrm{m}^{-2}(\mathrm{n}=71)$ workloads $)$ and those after surgery for pulmonary stenosis $\left(\boldsymbol{\Delta} ; \mathrm{n}=11\right.$, except at $25 \mathrm{~W} \cdot \mathrm{m}^{-2}(\mathrm{n}=10)$ and $70 \mathrm{~W} \cdot \mathrm{m}^{-2}$ $(n=9)$ workloads) at rest and for each workload.

compensated for by a significant rise in cardiac frequency in the PS group compared to controls $(\mathrm{p}=0.09)$. This fall in stroke volume bore no relationship to age at surgery or age at testing.

Maximum exercise performance and anaerobic threshold z-scores (control (mean, 95\% CI): 0, -0.2-0.2; PS: $0.20,-0.48-0.87)$ were very similar to normal with no discernible effects with age or at time from surgery.

\section{Discussion}

This study demonstrates that a low postnatal pulmonary blood flow/pressure of sufficient severity to necessitate surgery had small but significant effects on subsequent cardiopulmonary development and performance as judged by noninvasive measurements. To avoid spurious findings, care was taken only to recruit patients now regarded as "normal" with a treated "single, pure lesion" not confounded by, for example a patent arterial duct, which would inevitably change pulmonary haemodynamics. The

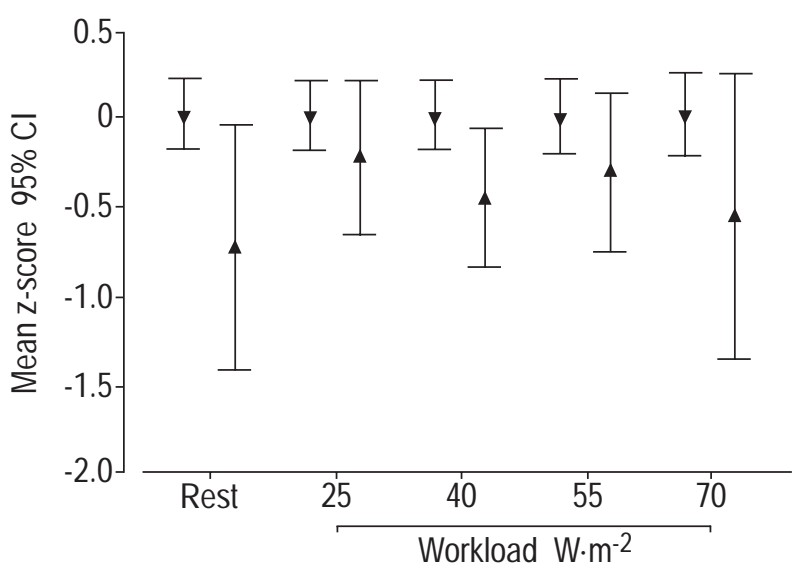

Fig. 7. - Mean (95\% confidence interval (CI)) z-scores for diffusion (transfer) constant in control children $\left(\mathbf{\nabla} ; \mathrm{n}=103\right.$, except at $55 \mathrm{~W} \cdot \mathrm{m}^{-2}$ $(\mathrm{n}=96)$ and $70 \mathrm{~W} \cdot \mathrm{m}^{-2}(\mathrm{n}=70)$ workloads) and those after surgery for pulmonary stenosis $\left(\boldsymbol{\Delta} ; \mathrm{n}=11\right.$, except at $25 \mathrm{~W} \cdot \mathrm{m}^{-2}(\mathrm{n}=10)$ and $70 \mathrm{~W} \cdot \mathrm{m}^{-2}$ $(\mathrm{n}=9)$ workloads) at rest and for each workload. "purity" of the sample led, however, to a relatively small number of study patients which may reduce the ability to detect physiological differences. To avoid technical errors due to personnel or time, tests in normal and PS subjects were performed under identical conditions by a single investigator (M. Rosenthal) in an albeit nonformal random order over the same period. All growth and sex parameters were also controlled for as far as possible between the control and study groups by the use of z-scores.

At rest, there was a reduced FEV1, cardiac frequency and transfer constant together with a raised effective FRC oxygen consumption and AVO in the PS group. During exercise, the cardiac frequency was less than that of the controls at each stage of exercise but rose proportionately more from rest than the controls. If the fall in stroke volume at peak exercise represents an in vivo manifestation of Starling's law of the heart [17], then the more marked fall in stroke volume in the PS group may be a manifestation of abnormal cardiac function despite normal echocardiography at rest.

Largely owing to the persistently raised FRC, the transfer constant remained subnormal, although the percentage rise in the constant from rest to peak exercise was normal. The implication of this is that the number of functioning alveolar capillary units at rest are fewer than normal, but during exercise, the proportion recruited is normal; however, the absolute number remains subnormal. Whether this effect (fewer functioning alveolar capillary units) is a primary problem or a secondary consequence of the failure to maintain a stroke volume at peak exercise cannot be determined from this study. However, given the similar effective pulmonary flows in the subject group compared to normal group implies that stroke volume may be important in this regard. From the reduced FEV1 and raised FRC, the effect may be more pulmonary than circulatory, although a normal alveolar ventilation and physiological deadspace militates against it. Overall, the conclusion that might be drawn is that the lungs are "smaller" than normal but function normally.

The above generally accords with the work in 10 nonsmoking untreated PS adults by DE TROYER et al. [29]. where similar conclusions were drawn using differing methodologies, i.e. plethysmographic FRC and airway resistance to derive conductance and static recoil pressures from pneumotachograph data. Their patient group had a lower vital capacity, total lung capacity (TLC), FEV1 and specific lung compliance, but no difference in FRC or residual volume compared to normal, which is surprising as the reduced FEV1 and compliance may also suggest airway obstruction. However, the relationship of the lung volume expressed as a percentage of TLC to static recoil pressure was normal, implying that the lungs in PS were small but normal. There was also a significantly reduced transfer factor and transfer constant. These authors inferred that an abnormality occurred in lung parenchymal growth and that a low specific compliance suggested the ratio of lung tissue to air per unit of lung volume was increased, although no evidence was presented to corroborate this. DE TROYER et al. [29] speculated that alveoli are decreased more in size than in number, but their group does represent an untreated group in adult life. Postnatal pulmonary artery obstruction leads to a reduction in radiological lung volume, which is restored after its relief [7]. FINNEGAN et al. [30] studied 14 catheterized adults, a mean of $7 \mathrm{yrs}$ after 
Table 2. - Comparison of percentage change (difference/original $\times 100$ ) at maximum exercise or after 9 min recovery from each subject's own initial resting value

\begin{tabular}{|c|c|c|c|}
\hline & & \multicolumn{2}{|c|}{ Percentage change from subject's initial resting value } \\
\hline & & $\begin{array}{c}\text { Control } \\
\text { Mean }(95 \% \mathrm{CI})\end{array}$ & $\begin{array}{c}\text { Treated pulmonary stenosis } \\
\text { Mean }(95 \% \mathrm{CI})\end{array}$ \\
\hline \multirow[t]{2}{*}{ Effective pulmonary blood flow } & Maximum exercise & $143(132-155)$ & $123(96-151)$ \\
\hline & After 9 min rest & $9(4-14)$ & $26(6-50)$ \\
\hline \multirow[t]{2}{*}{ Heart rate } & Maximum exercise & $104(99-112)$ & $124(108-142)^{+}$ \\
\hline & After 9 min rest & $24(22-29)$ & $26(19-34)$ \\
\hline \multirow[t]{2}{*}{ Stroke volume } & Maximum exercise & $18(12-33)$ & $-7(-17-11)^{* *}$ \\
\hline & After 9 min rest & $-14(-18--10)$ & $0.5(-18-20)$ \\
\hline \multirow[t]{2}{*}{ Oxygen consumption } & Maximum exercise & $447(413-500)$ & $446(341-562)$ \\
\hline & After 9 min rest & $31(15-51)$ & $36(-1-83)$ \\
\hline \multirow[t]{2}{*}{ Arteriovenous oxygen difference } & Maximum exercise & $130(116-147)$ & $145(110-184)$ \\
\hline & After 9 min rest & $22(15-51)$ & $9(-10-27)$ \\
\hline \multirow[t]{2}{*}{ Transfer factor } & Maximum exercise & $38(33-46)$ & $33(6-63)$ \\
\hline & After 9 min rest & $-3(-5-1)$ & $1(-9-13)$ \\
\hline \multirow[t]{2}{*}{ Functional residual capacity } & Maximum exercise & $18(13-26)$ & $4(-15-24)$ \\
\hline & After 9 min rest & $9(5-15)$ & $5(-5-15)$ \\
\hline \multirow[t]{2}{*}{ Transfer constant } & Maximum exercise & $20(15-29)$ & $28(14-43)$ \\
\hline & After 9 min rest & $-10(-13--6)$ & $-2(-13-9)$ \\
\hline \multirow[t]{2}{*}{ Transit time } & Maximum exercise & $-42(-44--39)$ & $-40(-52--27)$ \\
\hline & After 9 min rest & $-9(-11--2)$ & $-17(-32--1)$ \\
\hline
\end{tabular}

CI: confidence interval. ${ }^{+}: \mathrm{p}<0.03$ between control and subject group; ${ }^{* *}: \mathrm{p}=0.01$ between control and subject group.

surgery (age range at surgery 5-49 yrs), at rest and after one stage of exercise. They concluded that the cardiac output/oxygen consumption relationship was normal on exercise and noted that the stroke volume index (stroke volume/unit surface area) rose in 11 but fell in three. There was not the expected decrease in right ventricular enddiastolic pressure during exercise, and this was interpreted as being due to impaired right ventricular compliance secondary to myocardial hypertrophy or fibrosis. KRABIL et al. [31], exercised 24 adults and 53 children whilst catheterized prior to PS surgery. The children with the smallest pulmonary valve area $<0.5 \mathrm{~cm}^{2}$ responded to exercise by raising their right ventricular end-diastolic pressure and lowering their stroke volume index, but those children with larger pulmonary valve areas appeared to respond normally, although there were no controls for comparison. Untreated adults with PS achieved $94 \%$ of predicted maximum exercise response, significantly less than normal, though only $12 \%$ had a maximum performance outside the normal range.

In the present study, although there were trends to suggest that a delay in surgery exaggerated the findings, they failed to reach significance. This is partly a function of the sample size, but may also reflect a dominant antenatal or very early (weeks) postnatal effect on alveolar/capillary growth.

It would be unwise to compare results such as these with histological features found in conditions such as pulmonary atresia [5] as their local haemodynamics, presence of a patent arterial duct, etc. introduce too many confounding variables.

The finding of a raised oxygen consumption and AVO during rest and exercise in the PS group, but a similar percentage rise at maximum exercise, compared to controls was unexpected. This implies either that there is a fixed inefficiency in skeletal muscle in the PS group that does not change with exercise or that the control and study groups had differing body compositions, which is not borne out by the skinfold thickness measurements. Increased anxiety in the PS group compared to controls is unlikely as the PS group had a slower cardiac frequency.

All PS children had echocardiography to assess current right ventricular outflow tract status, and all were determined as being excellent. The status immediately after surgery is less certain, and it is at this age $(<3$ yrs $)$ that alveolar development principally occurs.

It would of course have been ideal to perform lung biopsies and count alveolar capillary numbers coincident with the in vivo measurements to confirm the above discussion, although clearly, this would have been ethically impossible. It would be relevant to investigate the independent effects of a noncardiac sternotomy on lung function and to compare them also with PS children treated with balloon dilation, although this cohort is only just reaching a suitable age for testing.

In conclusion, children after pulmonary stenosis surgery clearly function very well, and maximum exercise performance is not compromised. Nevertheless, this study demonstrates that subtle differences can be detected using a comparatively simple noninvasive method in children treated for pulmonary stenosis and that these changes need to be considered when contemplating treatment.

Acknowledgements: The authors thank M. Josen for kindly undertaking the echocardiographic examination.

\section{References}

1. Heath D, Edwards JE. The pathology of hypertensive pulmonary vascular disease. Circulation 1958; 18: 533547.

2. Heath D, Helmholz HF, Burchell HB, DuShane JW, Edwards JE. Graded pulmonary vascular changes and haemodynamic findings in cases of atrial and ventricular septal defect and patent ductus arteriosus. Circulation 1958; 18: 1155-1166. 
3. Heath D, Helmholz HF, Burchell HB, DuShane JW, Kirklin JW, Edwards JE. Relation between structural changes in the small pulmonary arteries and the immediate reversibility of pulmonary hypertension following closure of ventricular and atrial septal defects. Circulation 1958; 18: 1167-1174.

4. Rabinovitch M, Haworth SG, Castenada AR, Nadas AS, Reid LM. Lung biopsy in congenital heart disease: a morphometric approach to pulmonary vascular disease. Circulation 1978; 58: 1107-1122.

5. Haworth SG, Reid L. Quantitative structural study of pulmonary circulation in the newborn with pulmonary atresia. Thorax 1977; 32: 129-133.

6. Hislop A, Reid L. Structural changes in the pulmonary arteries and veins in tetralogy of Fallot. Br Heart J 1973; 35: $1178-1183$.

7. Fletcher BD, Garcia EJ, Colenda C, Borkat G. Reduced lung volume associated with acquired pulmonary artery obstruction in children. Am J Roentgenol 1979; 133: 4752.

8. Haworth SG. Pathophysiological and metabolic manifestations of pulmonary vascular disease in children. Herz 1992; 17: 254-261.

9. Forster RE, Roughton FJW, Kreuzer F, Briscoe WA. Photocolorimetry determination of rate of uptake of $\mathrm{CO}$ and $\mathrm{O}_{2}$ by reduced human red cell suspensions at $37^{\circ} \mathrm{C} . \mathrm{J}$ Appl Physiol 1957; 11: 260-268.

10. Forster RE, Roughton FJW, Cander L, Briscoe WA, Kreuzer F. Apparent pulmonary diffusing capacity for CO at varying alveolar $\mathrm{O}_{2}$ tensions. J Appl Physiol 1957; 11: 277-289.

11. Roughton FJW, Forster RE, Cander L. Rate at which carbon monoxide replaces oxygen from combination with human haemoglobin in solution and in the red cell. $J$ Appl Physiol 1957; 11: 269-276.

12. Roughton FJW, Forster RE. Relative importance of diffusion and chemical reaction rates in determining rate of exchange of gases in the human lung with special reference to true diffusing capacity of pulmonary membrane and volume of blood in the lung capillaries. $J \mathrm{Appl}$ Physiol 1957; 11: 290-302.

13. Davies NJH. Does the lung work? 4. What does the transfer of carbon monoxide mean? Br J Dis Chest 1982; 76: 105-124.

14. Scheid P, Piiper J. Diffusion. In: Crystal RG, West JB, eds. The Lung. New York, Raven Press, 1991; pp. 1681-1691.

15. Shaheen SO, Barker DJP. Early lung growth and chronic airflow obstruction. Thorax 1994; 49: 533-536.

16. Thurlbeck WM. Postnatal human lung growth. Thorax 1982; 37: 564-571.
17. Rosenthal M, Bush A. Haemodynamics in children during rest and exercise. Eur Respir J 1998; 11: 854-866.

18. Rosenthal M, Deanfield JE, Bush A, Redington A. A comparison of cardiopulmonary function in children undergoing the atriopulmonary or total cavopulmonary connection Fontan procedure. Circulation 1995; 91: 372-378.

19. Rosenthal M, Redington A, Bush A. Cardiopulmonary physiology after surgical closure of asymptomatic secundum atrial septal defects in childhood: exercise performance is unaffected by age at repair. Eur Heart J 1997; 18: $1816-1822$.

20. Standardisation of spirometry - 1987 update. Am Rev Respir Dis 1991; 136: 1285-1298.

21. Rosenthal M, Bain SH, Cramer D, et al. Lung function in white children aged $4-19$ years: I - Spirometry. Thorax 1993; 48: 794-802.

22. Bowyer J, Warner JO, Denison DM. Effective pulmonary blood flow in normal children at rest. Thorax 1988; 43: 972-977.

23. Bush A, Busst C, Johnson S, Denison DM. Rebreathing method for the simultaneous measurement of oxygen consumption and effective pulmonary blood flow during exercise. Thorax 1988; 43: 268-275.

24. Cander L, Forster RE. Determination of pulmonary parenchymal tissue volume and pulmonary capillary flow in man. J Appl Physiol 1959; 14: 541-551.

25. Petrini MF, Peterson BT, Hyde RW. Lung tissue volume and blood flow by rebreathing: theory. J Appl Physiol 1978; 44: 795-802.

26. Sackner MA, Greeneltch D, Heiman MS, Epstein S, Atkins N. Diffusing capacity, membrane diffusing capacity, capillary blood volume, pulmonary tissue volume, and cardiac output measured by a rebreathing technique. Am Rev Respir Dis 1975; 111: 157-165.

27. Davis NJH, Denison DM. The measurement of metabolic gas exchange and minute volume by mass spectroscopy alone. Respir Physiol 1979; 36: 261-267.

28. Beaver WL, Wasserman BJ, Whipp A. A new method for detecting anaerobic threshold by gas exchange. $J$ Appl Physiol 1986; 60: 2020-2027.

29. DeTroyer A, Yernault J-C, Englert M. Lung hypoplasia in congenital pulmonary valve stenosis. Circulation 1977; 56: 647-651.

30. Finnegan P, Ibenacho HNC, Sigh SP, Abrams LD. Haemodynamic studies at rest and during exercise in pulmonary stenosis after surgery. Br Heart $J$ 1974; 36 : 913-918.

31. Krabill KA, Wang Y, Einzig S, Moller JH. Rest and exercise haemodynamics in pulmonary stenosis: comparison of children and adults. Am J Cardiol 1985; 56: 360-365. 